\title{
A retrospective analysis of maternal mortality in an urban tertiary care hospital
}

\author{
Nishu Bhushan, Aakriti Manhas*, Anju Dogra \\ Department of Obstetrics and Gynecology, Government Medical College, Jammu, J\&K, India
}

Received: 22 November 2021

Revised: 13 December 2021

Accepted: 14 December 2021

\section{*Correspondence:}

Dr. Aakriti Manhas,

E-mail: aakritimanhas660@gmail.com

Copyright: (C) the author(s), publisher and licensee Medip Academy. This is an open-access article distributed under the terms of the Creative Commons Attribution Non-Commercial License, which permits unrestricted non-commercial use, distribution, and reproduction in any medium, provided the original work is properly cited.

\section{ABSTRACT}

Background: The aims of the study were to generate information regarding causes and complications leading to maternal deaths in an urban tertiary care centre and to find if any of the causes are preventable.

Methods: The medical records of all maternal deaths occurring over a period of 4 years between January 2015 and December 2018 were reviewed.

Results: Maternal mortality ratio ranged between 127 and 48 per 1, 00,000 births in the study. The causes of deaths were haemorrhage $(29.47 \%)$, pregnancy-induced hypertension (PIH) $(28.42 \%)$, anaemia $(12.63 \%)$, sepsis $(9.47 \%)$, thromboembolism $(6.31 \%)$, hepatic causes $(5.26 \%)$, blood reactions $(3.15 \%)$, heart diseases $(2.10 \%)$, central nervous system (CNS) related (1.05\%) and others (2.10\%). Maximum deaths occurred in women between 21-30 years of age. Mortality was highest in post-natal mothers $(70.52 \%)$.

Conclusions: Overall maternal mortality due to direct obstetric causes was (73.68\%), indirect obstetric causes $(22.10 \%)$ and unrelated causes $(4.2 \%)$.

Keywords: Maternal mortality, Direct obstetric death, Indirect obstetric death, Unrelated deaths

\section{INTRODUCTION}

Maternal mortality ratio (MMR) is number of maternal deaths (MD's) per 100,000 live births during a given period. Maternal mortality rate is number of maternal deaths in a given period per 100,000 women of reproductive age during the same period. ${ }^{1}$ Direct MD is the result of a complication of the pregnancy, delivery, or their management. Indirect MD is a pregnancy-related death in a patient with pre-existing or newly developed health problem. Late MD is defined as the death of a woman from direct or indirect cause $>42$ days but $<1$ year after termination of pregnancy. The MMR has declined to 113 in 2016-2018 from 122 in 2015-2017 and 130 in 2014-16, according to the special bulletin on maternal mortality in India 2016-2018, released by the office of the registrar general's sample registration system (SRS). The objectives of the study were to generate information regarding causes and complications leading to maternal deaths in an urban tertiary care centre and to find if any of the causes are preventable.

\section{METHODS}

SMGS Hospital Jammu is a tertiary care centre of Jammu province of the union territory of Jammu and Kashmir. It gets referrals from maternity homes, polyclinics, district and primary health centres. It was a record based retrospective study carried out in the department of obstetrics and gynaecology at SMGS Hospital Jammu between January 2015 and December 2018. The medical records of all maternal deaths occurring in the peripartum period during the study period were reviewed irrespective to place of delivery and correlated with various factors like age, parity, hospital antenatal supervision, delivery status, admission death interval and causes of deaths. 
The study was conducted after obtaining approval from the institutional ethics committee. The statistical data was analysed using Microsoft excel and results were presented in the form of percentages.

\section{RESULTS}

Between January 2015 and December 2018, total number of deliveries was 84,086 and maternal deaths were 95. Year wise distribution of deliveries, MD's and yearly MMR are shown in Table 1.

Highest mortality of $68.42 \%$ was noted in the age group of 21-30 years while mortality of $10.52 \%$ and $21.05 \%$ was noted in women aged $<20$ and $>30$ years respectively (Tables 2 and 3). In our study postnatal death rate was $70.52 \%$ and antenatal death rate was $29.46 \%$. Postnatal maternal deaths include $36.84 \%$ deaths after vaginal delivery and $33.68 \%$ deaths after lower segment caesarean section (LSCS). Antenatal deaths include $10.52 \%$ early pregnancy deaths (septic abortion and ectopic deaths).

Multigravida women (upto gravida three) had maximum MMR of $38.94 \%$ while primi and grand multigravida comprised $36.84 \%$ and $24.21 \%$ respectively. Direct obstetrical deaths occurred in $73.68 \%$, indirect obstetric deaths in $22.10 \%$ and deaths due to unrelated causes in $2.10 \%$. Direct obstetrical deaths include death from haemorrhage $29.47 \%$, PIH $28.42 \%$, sepsis $9.47 \%$ and thromboembolism $6.31 \%$. Year wise distribution of direct obstetric deaths is illustrated in Table 4. Indirect obstetric deaths occurred in $22.10 \%$ women and included deaths due to hepatic causes $5.26 \%$, anaemia $12.63 \%$, heart diseases $2.10 \%$, CNS diseases $1.05 \%$ and fever $1.05 \%$. Unrelated causes include blood reactions $3.15 \%$ and diabetic ketoacidosis (DKA) $1.05 \%$. Year wise distribution of indirect obstetric deaths is illustrated in Table 5.

Table 1: Year-wise distribution of deliveries and maternal deaths.

\begin{tabular}{|llll|}
\hline Year & Deliveries & Maternal deaths & MMR/1,00,000 births \\
\hline $\mathbf{2 0 1 5}$ & 19,617 & 25 & 127 \\
\hline $\mathbf{2 0 1 6}$ & 20,309 & 34 & 167 \\
\hline $\mathbf{2 0 1 7}$ & 21,200 & 25 & 118 \\
\hline $\mathbf{2 0 1 8}$ & 22,960 & 11 & 48 \\
\hline Total & 84,086 & 95 & 113 \\
\hline
\end{tabular}

MMR: Maternal mortality ratio

Table 2: Maternal deaths as per age.

\begin{tabular}{|c|c|c|c|c|}
\hline Years & $\begin{array}{l}\text { Number of women }<20 \\
\text { years of age }\end{array}$ & $\begin{array}{l}\text { Number of women 21-30 } \\
\text { years of age }\end{array}$ & $\begin{array}{l}\text { Number of women } \\
>31 \text { years of age }\end{array}$ & $\begin{array}{l}\text { Number of } \\
\text { maternal deaths }\end{array}$ \\
\hline 2015 & 3 & 16 & 6 & 25 \\
\hline 2016 & 4 & 26 & 4 & 34 \\
\hline 2017 & 3 & 18 & 4 & 25 \\
\hline 2018 & - & 5 & 6 & 11 \\
\hline Total (\%) & $10(10.52)$ & $65(68.42)$ & $20(21.05)$ & 95 \\
\hline
\end{tabular}

Table 3: Delivery methods and maternal deaths.

\begin{tabular}{|llc|}
\hline Variable & Number of maternal deaths & Percentage $(\%)$ \\
\hline Antenatal (undelivered) & 18 & 18.94 \\
\hline Postnatal (vaginal) & 35 & 36.84 \\
\hline Postnatal (LSCS) & 32 & 33.68 \\
\hline Early pregnancy deaths & 10 & 10.52 \\
\hline Total deaths & 95 & \\
\hline
\end{tabular}

Table 4: Year wise distribution of direct obstetric deaths.

\begin{tabular}{|lllll|l|}
\hline Year & Haemorrhage & PIH & Embolism & Sepsis & Total \\
\hline $\mathbf{2 0 1 5}$ & No. $(\boldsymbol{\%})$ & No. $(\boldsymbol{\%})$ & No. $(\boldsymbol{\%})$ & No. $(\boldsymbol{\%})$ & 21 \\
\hline $\mathbf{2 0 1 6}$ & $11(44)$ & $5(20)$ & $3(12)$ & $2(8.10)$ & 21 \\
\hline $\mathbf{2 0 1 7}$ & $9(26.47)$ & $8(23.52)$ & $2(5.88)$ & $5(14.70)$ & 24 \\
\hline $\mathbf{2 0 1 8}$ & $5(20)$ & $10(40)$ & $1(4.10)$ & $1(4.10)$ & 17 \\
\hline Total $(\boldsymbol{\%})$ & $3(27.27)$ & $4(36.36)$ & - & $1(9.09)$ & 8 \\
\hline
\end{tabular}


Table 5: Year wise distribution of indirect obstetric deaths.

\begin{tabular}{|c|c|c|c|c|c|c|}
\hline Year & Hepatic causes & $\begin{array}{l}\text { Fever } \\
\text { No. }(\%)\end{array}$ & Anaemia & $\begin{array}{l}\text { Heart diseases } \\
\text { No. }(\%)\end{array}$ & CNS diseases & Total \\
\hline 2015 & $2(8)$ & $1(1.05)$ & $2(8)$ & - & - & 5 \\
\hline 2016 & $3(8.82)$ & - & $3(8.82)$ & $1(2.94)$ & $1(2.94)$ & 8 \\
\hline 2017 & - & - & $4(16)$ & $1(4)$ & - & 5 \\
\hline 2018 & - & - & $3(27.27)$ & - & - & 3 \\
\hline Total (\%) & 5.26 & 1.05 & 12.36 & 2.10 & 1.05 & $21(22.10)$ \\
\hline
\end{tabular}

\section{DISCUSSION}

Maternal death or maternal mortality is defined by the World Health Organisation (WHO) as "the death of a woman while pregnant or within 42 days of termination of pregnancy, irrespective of the duration and site of pregnancy, from any cause related to or aggravated by the pregnancy or its management but not from accidental or incidental causes". 2

By 2017, the world maternal mortality rate had declined $44 \%$ since 1990 , but still everyday 830 women die from pregnancy or child birth related causes. ${ }^{3}$

The global maternal mortality rate has fallen from 385 maternal deaths per 100,000 live births in 1990 to 216 deaths per 100,000 live births in 2015 and many countries have halved their maternal death rates in last 10 years. ${ }^{3}$

Maternal mortality is the index of reproductive health of a society. High incidence of maternal deaths reflects a poor quality of maternal resources, late referral and low socioeconomic status of the community. The mean maternal mortality rate in the study period of 4 years was $112.97 / 100,000$ births.

Murthy et al observed a MMR of 302.23/100,000 live births. ${ }^{4}$

Mootha et al evaluation of MMR at a high volume tertiary referral centre: what are we missing? A study observed MMR of 341.90/100,000 live births. ${ }^{5}$

Patel et al observed a higher mean MMR of 413.3/100,000 live births. ${ }^{6}$

In our study, $68.42 \%$ of maternal deaths were in the age group of 21 to 30 years as highest number of women belongs to this age group. Puri et al also observed maximum deaths $(71.53 \%)$ in this age group. ${ }^{7}$ Studies conducted by Garg et al and Khandale et al showed maximum deaths in 25-29 years age group. ${ }^{8,9}$

$63.15 \%$ maternal deaths were reported in multiparous patients in our study similar observation was seen in studies conducted by Petal et al, Garg et al and Khumanthem et al but study done by Mediratta et al showed more deaths among primigravidae patients. ${ }^{6,8,10,11}$ Admission death interval analysis of our study revealed that $51.57 \%$ of women died within 24 hours of admission due to poor general condition of women on admission, late referrals and at times due to long travel from the referral hospital. Many patients had to travel a distance of 150 to 200 kilometres to reach our hospital. Most of these deaths are preventable if patients are given appropriate treatment at periphery and timely referral to higher centres. Training of medical officers and staff nurses working in rural areas give a ray of hope of reducing maternal mortality.

More than half $(70.52 \%)$ of maternal deaths occurred in post-partum period and included $36.84 \%$ deaths after vaginal delivery and $33.68 \%$ deaths after LSCS. Antenatal women constituted $29.46 \%$ of all maternal deaths and included $10.52 \%$ of early pregnancy deaths (septic abortions and ectopic deaths).

In our study, $73.68 \%$ deaths were due to direct causes and $22.10 \%$ maternal deaths were due to indirect cause. Various other studies also showed that maximum deaths were due to direct cause but Sreekumari et al in their study found that indirect cause predominated and amounted to $50.49 \%$ while direct causes accounted for $42.57 \%$ deaths. ${ }^{4,6,8-10,13,14}$

In our study, direct obstetric deaths (73.68\%) include deaths from haemorrhage $29.47 \%$, PIH $28.42 \%$, sepsis $9.47 \%$ and thromboembolism $6.31 \%$. Even today, a large number of maternal deaths is due to the classical triad of haemorrhage, PIH and sepsis. All these are preventable causes of maternal mortality provided treatment is instituted in time.

Haemorrhage especially during the post-partum is sudden, unpredictable and is more dangerous when the woman has pre-existing anemia. In our study rate of death due to haemorrhage was $29.47 \%$. Haemorrhage related deaths can be decreased by liberal use of blood and component transfusions, vigorous fluid replacement and follow-up with advanced investigation facilities.

PIH accounted for $28.42 \%$ of maternal death in our study. Active and timely use of magnesium sulphate regimen, better investigation and monitoring facilities and vigorous management techniques can decrease deaths due to PIH. Maternal death can be prevented by improving the health care facilities in rural areas by ensuring round the clock availability of certain basic drugs like injection magnesium sulphate, tablet misoprostol, injection oxytocin, injection methergin as most maternal deaths in 
rural areas are still due to eclampsia and post-partum haemorrhage.

Indirect cause accounted for $22.10 \%$ of maternal deaths in are study and included deaths due to anemia $12.63 \%$, hepatic cause $5.26 \%$, cardiac cause $2.10 \%$, CNC cause $1.05 \%$ and fever $1.05 \%$.

Unrelated cause constituted $4.20 \%$ of all the maternal deaths in our study. They include blood reaction $3.15 \%$ and ketoacidosis $1.05 \%$.

It is important to mention that our study has limitations. Since it is a retrospective study, there may be records with poor documentation. Additionally the present information was one hospital; more multicenter studies should be done in the future.

\section{CONCLUSION}

Haemorrhage, PIH and sepsis are the major causes of maternal deaths and each of them is considered potentially preventable cause of maternal death.

Poor nutritional status, lack of antenatal care, unawareness of warning signs of pregnancy, unsupervised/dai-handled deliveries and late referrals are the major contributory factors leading to poor maternal prognosis.

There should be active management of high risk group by frequent ANC visits, direct consultant supervision, liberal use of CTG, colour Doppler study, biochemical markers, fluid and component transfusions, aggressive management of infection and closer monitoring of women in labor. Vigorous mass campaign for community based maternal education programme should be the top priority of all maternal and child health programs.

Improvement in primary health care in rural areas and proper implementation of NHM programs and upgradation of hospitals can definitely bring down the number of maternal deaths.

\section{Funding: No funding sources}

Conflict of interest: None declared

Ethical approval: The study was approved by the Institutional Ethics Committee

\section{REFERENCES}

1. Maternal death. Available at: http://en.wikipedia. org/wiki/maternaldeath. Accessed on 24 July 2021.
2. World Health Organization. "Health statistics and information systems: Maternal mortality ratio (per 100000 live births)". Accessed on 17 June 2016.

3. “Maternal health". United Nations Population Fund. Accessed on 29 January 2017.

4. Murthy BK, Murthy MB, Prabhu PM. Maternal Mortality in a tertiary care hospital: A 10-year Review. Int J Prev Med. 2013;4(1):105-9.

5. Mootha S, Bathula UR. Evaluation of Maternal Mortality Rate (MMR) at a High Volume Tertiary Referral Center; What are we Missing? A study spanning 85, 404 Live Births over 9 years. Int J Sci Res. 2013;4:438.

6. Patel DM, Salat VK, Patel MM. Impact of counselling on selecting a hormonal contraceptive method. Int $\mathbf{J}$ Reprod Contracept Obstet Gynecol. 2018;7(6):22836.

7. Puri A, Yadav I, Jain N. Maternal mortality in an urban Tertiary care hospital of north India. J Obstet Gynaecol India. 2011;61:280-5.

8. Garg P. To study maternal mortality and complications leading to maternal death in the tertiary care centre. Int J Med Res Rev. 2016;4(3):347-52.

9. Khandale SN, Kedar K. Analysis of maternal mortality: a retrospective study at tertiary care centre. Int J Reprod Contracept Obstet Gynecol. 2017;6(4):1610-3.

10. Khumanthem PD, Chanam MS, Samjetshabam RD. Maternal mortality and its causes in a tertiary center. J Obstet Gynecol India. 2012;62(2):168-71.

11. Mediratta G, Khullar H, Bhandari SK. An observational study of maternal mortality in a tertiary care hospital in New Delhi. J Indian Acad Clini Med. 2015;16(2).

12. Sundari KM, Jayanthi RD, Ramasamy B. Trends in maternal mortality in a tertiary care hospital. Int $\mathbf{J}$ Reprod Contracept Obstet Gynecol. 2016;5(11):365962.

13. Narlawar UW, Lilare RR, Nisal K. A comparative study on maternal mortality at government medical college, Nagpur. Indian J Appl Res. 2018;8(1).

14. Sreekumari U, Nair S. (2019). Trends in Causes of Maternal Mortality in a Tertiary Care Centre in Kerala after Introduction of CRMD and Quality Standards Programme. JMSCR. 2019;7(1):579-85.

Cite this article as: Bhushan N, Manhas A, Dogra A. A retrospective analysis of maternal mortality in an urban tertiary care hospital. Int J Reprod Contracept Obstet Gynecol 2022;11:197-200. 